\title{
KEBIJAKAN KERUKUNAN ANTAR UMAT BERAGAMA \\ DI DESA BALUN, KAB. LAMONGAN
}

\author{
Farah Damayanti
}

\section{Pegawai Negeri Sipil Kabupaten Lamongan}

\begin{abstract}
Indonesian society has local cultures and traditions that are functionally able to maintain the environment situation in order to remain harmonious, both with fellow humans and the environment. These local traditions have important meanings and values, among others, as a reference for the behavior of the people in living their lives, including facing differences in interacting with different people culture. These local traditions are actually the expression of local knowledge or local wisdom of a community in response to their environmental situation. Balun Community Balun Village, Turi Subdistrict, Lamongan Regency is able to maintain religious harmony, even though they have different religions. This is due to the existence of elements which become social glue in the form of local wisdoms that live in Balun society. Substantially, local wisdom is the values that apply in a society. These values are believed to be true and become a reference in the daily behavior of the local community. These values of local wisdom are seen as entities that determine the dignity and human dignity of the community because they contain elements of creative intelligence and local knowledge from the elites and their communities.
\end{abstract}

Keywords: Local Wisdom, Tolerance, Balun 


\section{Pendahuluan}

Kearifan lokal adalah nilai-nilai yang berlaku dalam suatu masyarakat. Nilai-nilai tersebut diyakini kebenarannya dan menjadi acuan dalam bertingkah laku sehari-hari masyarakat setempat. Nilai-nilai kearifan lokal ini dipandang sebagai entitas yang sangat menentukan harkat dan martabat manusia dalam komunitasnya karena di dalamnya berisi unsur kecerdasan kreativitas dan pengetahuan lokal dari para elit dan masyarakatnya. Nilai-nilai kearifan lokal dalam bentuk tradisi maupun norma-norma sosial di masyarakat secara fungsional dapat memperkuat sistem budaya sebagai acuan dalam kehidupan masyarakat, yang kemudian dipercayai dan diakui sebagai elemen penting sehingga mampu mempertebal kohesi sosial diantara warga masyarakat. ${ }^{1}$ Dengan demikian kearifan lokal dapat menjadi elemen perekat (kohesi) sosial dalam kehidupan lintas agama, lintas kepercayaan, dan bahkan lintas budaya, sehingga dapat memberi warna kebersamaan secara dinamis dan damai, terutama dalam masyarakat yang multikultur.

\footnotetext{
1 John Haba, Revitalisasi Kearifan Lokal: Studi Resolusi Konflik di Kalimantan Barat, Maluku, dan Poso, (Jakarta: ICIP dan Eropean Commision, 2007), h. 11.
}

Masyarakat Jawa telah dikenal sebagai orang yang sangat menjunjung tinggi nilai-nilai kerukunan dan keharmonisan dalam masyarakat. Dalam penelitian tentang keluarga Jawa, Hildred Geertz $^{2}$ mengungkapkan dua kaidah penting yang mengatur sikap perilaku masyarakat Jawa hubungan sosial. Kaidah atau nilai kejawaan yang penting tentang kehidupan orang Jawa yang merupakan petunjuk moral yang mendasari tindak-tanduk atau perilaku dalam lingkungannya adalah pandangan tentang tata krama penghormatan, dan penampilan sosial yang harmonis.

Dua kaidah tersebut disimpulkan oleh Franz Magnis Suseno ${ }^{3}$, dalam kajiannya tentang Etika Jawa, sebagai prinsip hormat dan prinsip rukun. Prinsip rukun menuntut agar manusia dalam berbicara dan membawa diri harus selalu menunjukkan sikap hormat kepada orang lain sesuai derajat dan kedudukannya. Sedangkan prinsip kedua menuntut agar dalam setiap situasi manusia hendaknya bersikap sedemikian rupa sehingga tidak sampai menimbulkan konflik. Dengan demikian, setiap orang dalam masyarakat Jawa

\footnotetext{
2 Hildred Geertz, Keluarga Jawa, (Jakarta: Grafiti Press, 1985), h. 151.

3 Franz Magnis Suseno, Etika Jawa, Sebuah Analisa Falsafi tentang Kebijaksanaan Hidup Jawa, (Jakarta: PT. Gramedia Pustaka Utama, 2003), h. 38.
} 
diharapkan berperilaku sesuai dengan dua prinsip tersebut. Hal ini menjadikan dalam masyarakat yang berlatar belakang Jawa mampu memelihara kerukunan.

Kearifan lokal sebagai bentuk kecerdasan lokal masyarakat mengatasi persoalan hidupnya, terutama yang berkaitan dengan hubungan atau interaksi sosial. Terlebih dalam masyarakat yang heterogen dan plural, terutama perbedaan agama, memiliki potensi terjadi konflik antarumat beragama. Tantangan semacam ini, tentunya mendorong masyarakat itu sendiri untuk memelihara nilai-nilai tradisi lokal yang mampu menyelesaikan atau meredam munculnya konflik tersebut. Di antara wilayah yang selama ini telah dikenal sebagai masyarakat yang plural tetapi mampu mempertahankan kerukunan adalah masyarakat Balun, yakni di desa Balun Kecamatan Turi Kabupaten Lamongan. Dimana meskipun mayoritas masyarakatnya memeluk agama Islam, tetapi di desa ini terdapat umat Kristen dan bahkan juga Hindu. Umat Islam, Kristen dan Hindu di wilayah Balun ini berinteraksi dengan baik dan tercipta kerukunan beragama. Tulisan ini bertujuan mendeskripsikan dinamika kerukunan dalam masyarakat Balun Desa Balun, Kecamatan Turi Kabupaten Lamongan, dan mengungkapkan ungkapan-ungkapan tradisional yang mendukung terpeliharanya kerukunan tersebut. Dari uraian di atas dapat di tarik permasalahan sebagai berikut: Bagaimana ajaran kearifan lokal di Balun bisa menciptakan toleransi antar umat beragama ? Bagaimana masyarakat di Balun melestarikan dan mensosialisasikan ajaran kearifan lokal tersebut? Berdasarkan pokok masalah yang telah dirumuskan penelitian ini mempunyai tujuan: Mengetahui Bagaimana ajaran kearifan lokal di Balun bisa menciptakan toleransi antar umat beragama. Mengetahui Bagaimana masyarakat di Balun melestarikan dan mensosialisasikan ajaran kearifan lokal tersebut.

Suatu kegiatan diharapkan mempunyai hasil dan manfaat, demikian juga dalam penelitian ini diharapkan mempunyai manfaat diantaranya sebagai berikut: Kegunaan Teoritis ; Memberikan kesimpulan baru bagaimana ajaran kearifan lokal bisa menciptakan kerukunan umat beragama. Menjadi rujukan tentang studi kearifan lokal dan toleransi keagamaan. 
Kegunaan Praktis; Menjadikan umat beragama lebih mengedepankan toleransi. Meminimalisir tindakan deskriminasi antar golongan, ras dan agama.

\section{Kearifan Lokal}

E. Tiezzi, N. Marchettini, \& M. Rossini menjelaskan kearifan lokal sebagai pengetahuan yang eksplisit yang muncul dari periode panjang yang berevolusi bersama-sama masyarakat dan lingkungannya dalam sistem lokal yang sudah dialami bersama-sama. Secara substansial, kearifan lokal itu adalah nilai-nilai yang berlaku dalam suatu masyarakat. Nilai-nilai yang diyakini kebenarannya dan menjadi acuan dalam bertingkah-laku sehari-hari masyarakat setempat. Kearifan yang tersebut diungkapkan dalam bentuk kata-kata bijak (falsafah) berupa nasehat, pepatah, pantun, syair, folklor (cerita lesan) dan sebagainya; aturan, prinsip, norma dan tata aturan sosial dan moral yang menjadi sistem sosial; ritus, seremonial atau upacara tradisi dan ritual; serta kebiasaan yang terlihat dalam perilaku sehari-hari dalam pergaulan sosial. ${ }^{4}$

\footnotetext{
4 Rohimin, et.al, Harmonisasi Agama dan Budaya di Indonesia, (Jakarta: Balai Litbang Agama Jakarta, 2009), h. 207.
}

Kearifan lokal adalah pandangan hidup dan ilmu pengetahuan serta berbagai strategi kehidupan yang berwujud aktivitas yang dilakukan oleh masyarakat lokal dalam menjawab berbagai masalah dalam pemenuhan kebutuhan mereka. Dalam bahasa asing sering juga dikonsepsikan sebagai kebijakan setempat "local wisdom" atau pengetahuan setempat "local knowledge" atau kecerdasan setempat "local genious".

Menurut Rahyono, kearifan local merupakan kecerdasan manusia yang dimiliki oleh kelompok etnis tertentu yang diperoleh melalui pengalaman masyarakat. Artinya, kearifan lokal adalah hasil dari masyarakat tertentu melalui pengalaman mereka dan belum tentu dialami oleh masyarakat yang lain. Nilai-nilai tersebut akan melekat sangat kuat pada masyarakat tertentu dan nilai itu sudah melalui perjalanan waktu yang panjang, sepanjang keberadaan masyarakat tersebut.

Ilmuwan antropologi, seperti Koentjaraningrat, Spradley, Taylor, dan Suparlan, telah mengkategorisasikan kebudayaan manusia yang menjadi wadah kearifan lokal itu kepada idea, aktivitas sosial, artifak. Kebudayaan merupakan keseluruhan pengetahuan 
yang dimiliki oleh sekelompok manusia dan dijadikan sebagai pedoman hidup untuk menginterpretasikan lingkungannya dalam bentuk tindakantindakannya sehari-hari.

$$
\text { Negara Indonesia sangat }
$$

majemuk dan mempunyai petatahpetitih Melayu, Bahasa kromo inggil Jawa, petuah yang diperoleh dari berbagai suku di Indonesia. Hal tersebut merupakan contoh keragaman ungkapan suku-suku bangsa yang menjadi bagian dari kearifan lokal, yang menjadi kendali dalam menjalankan kehidupan. Apa yang diutarakan dalam tulisan ini masih sangat minim, jika dibandingkan dengan seluruh suku-suku bangsa kita yang ada di nusantara (429 suku bangsa besar). Namun tulisan ini bermaksud mengetuk hati kita semua, bahwa kearifan budaya lokal berperan dalam pendidikan karakter bangsa.

Berikut ini merupakan beberapa contoh kearifan local yang berkembang dalam kehidupan bangsa Indonesia.

1. Aceh: Udep tsare mate syahid (hidup bahagia, meninggal diterima Allah Swt), Hukom ngon adat lagge zat ngon sifeut (antara hukum dengan adat seperti zat dengan sifatnya).
2. Melayu (Deli, Kalimantan Barat, Sibolga, Sumatra Barat): Lain lubuk lain ikannya, di mana bumi diinjak di situ langit dijunjung.

3. Batak: Hasangapon, hagabeon, hamoraon, sarimatua

(kewibawaan, kekayaan, keturunan yang menyebar, kesempurnaan hidup). Nilakka tu jolo sarihon tu pudi (melangkah ke depan pertimbangkan ke belakang).

4. Sumatra Barat: Bulek ai dek pambuluah, bulek kato jo mupakkek (bulat air karena pembuluh, bulat kata dengan mufakat); Adat ba sandi syara', syara' ba sandi kitabullah (adat berlandaskan hukum, hukum bersendikan kitab suci).

5. Wamena: Weak Hano Lapukogo (susah senang sama-sama); Ninetaiken O'Pakeat (satu hati satu rasa).

6. Bugis: Sipakatau (saling mengingatkan); Sipakalebbi (saling menghormati); Mali Siparappe, Rebba Sipatokkong (saling mengingatkan, saling menghargai, saling memajukan).

7. Manado: Baku Beking Pandei (saling memandaikan satu sama lainnya). 
8. Minahasa: Torang Samua

Basudara (kita semua bersaudara); Mapalus (gotong royong); Tulude-Maengket (kerja bakti untuk rukun), Baku-baku bae, bakubaku sayang, baku-baku tongka, bakubaku kase inga (saling berbaik-baik, sayang menyayangi, tuntun-menuntun, dan ingat mengingatkan); Sitou Timou, Tumou Tou (saling menopang dan hidup menghidupkan: manusia hidup dan untuk manusia lain).

9. Bolaang Mangondow: Momosat (gotong royong); Moto tabian, moto tampiaan, moto tanoban (saling mengasihi, saling memperbaiki dan saling merindukan).

10. Kaili: Kitorang bersaudara (persaudaraan); Toraranga (saling mengingatkan), Rasa Risi Roso Nosimpotobe (sehati, sealur pikir, setopangan, sesongsongan).

11. Poso: (Suku Pamona, Lore, Mori, Bungku dan Tojo/Una-Una, Ampana dan pendatang: Bugis, Makassar, Toraja, Gorontalo, Minahasa, Transmigrasi: Jawa, Bali, Nusa Tenggara): Sintuwu Maroso (persatuan yang kuat: walau banyak tantangan, masalah, tidak ada siapapun yang dapat memisahkan persatuan warga Poso tanpa memandang suku, agama, ras dan antargolongan).

12. Sulawesi Tenggara: Kolosara (supremasi Samaturu (Bahasa Tolala): Bersatu, gotong royong, saling menghormati; Depo adha adhati (Muna): saling menghargai.

13. Bali: Manyama braya (semua bersaudara), Tat Twam Asi (senasib sepenanggungan), $\quad T r i$ Hita Karana (tiga penyebab kebahagiaan), yakni Pariangan (harmoni dengan Tuhan), Pawongan (harmoni dengan sesama manusia), dan Palemahan (harmoni dengan lingkungan alam).

14. Jambi: Lindung melindung bak daun sirih, Tudung menudung bak daun labu, Rajut merajut bak daun petai (saling tolong menolong/ saling menghargai).

15. Jawa Timur: Siro yo ingsun, ingsun yo siro (kesederajatan atau egalitarianism), Antarantaran ugo (persaudaraan).

16. Pandeglang: Saman yang berfungsi sebagai kesenian, tarekat; jalan zikir dan ketenangan hati, serta simbolsimbol yang mempunyai kekuatan 
magis. Melalui kegiatan Saman masyarakat Pandeglang dapat menciptakan keharmonisan, kerukunan yang bersifat gotong royong dalam membangun kebersamaan sosial dan keagamaan di antara warganya, terutama bagi warga kelompok Saman, yang mengarah pada kehidupan bersama.

17. Kalimantan Selatan: Kayuh baimbai (bekerjasama), Gawi sabumi (gotong royong), Basusun Sirih (keutuhan), Menyisir sisi tapih (introspeksi).

18. Dayak Kanayatri: Adil ka'talimo, bacuramin ka'saruga, ba sengat ka'jubata (adil sesama, berkaca surgawi, bergantung pada Yang Esa); Rumah Betang (bersama dan saling tenggang); Handephabaring hurung (nilai kebersamaan dan gotong royong); Betang (semangat rumah panjang).

19. Dayak Bekati: Janji baba's ando (janji harus ditepati); Janji pua' take japu (jangan janji sekedar kata-kata).

20. Dayak Bahau: Murip ngenai (Makmur sejahtera); Te'ang liray (unggul di antara sesama: kompetisi sehat).
21. Provinsi Nusa Tenggara Barat: Saling Jot (saling memberi), Saling pelarangin (saling melayat), Saling ayon (saling mengunjungi; silahturahmi), Saling ajinin (saling menghormati), Patut (baik, terpuji, hal yang tidak berlebihlebihan), Patuh (rukun, taat, damai, toleransi, saling harga menghargai), Patju (rajin giat, tak mengenal putus asa), Tatas, Tuhu, Trasna (berilmu, berakhlak/etika, bermasyarakat).

22. Sasak (Lombok): Bareng anyong jari sekujung (bersama-sama lebur dalam satu), Embe aning jarum ito aning benang (ke mana arah jarum ke situ arah benang), Endang kelebet laloq leq impi (jangan terlalu terpesona oleh mimpi), Endaq ngegaweh marak sifat cupak (jangan memakai atau bersifat seperti cupak), Endaq ta beleqan ponjol dait kelekuk (jangan lebih besar tempat nasi dari pada tempat beras), Endaq ta ketungkulan dengan sisok nyuling (jangan terlena dengan siput menyanyi), Idepta nganyam memeri, beleqna embuq teloq (seperti usaha memelihara anak itik, sesudah besar memungut telurnya), Keduk lindung, bani 
raok (berani cari belut harus berani kena lumpur), Laton kayuq pasti tebaban isiq angin (setiap pohon pasti dilanda oleh angin).

Salah satu bentuk kearifan lokal tersebut adalah ungkapan-ungkapan tradisional. Ungkapan tradisional adalah kata atau kelompok kata yang memiliki makna kiasan, konotatif, simbolis yang berasal dari tradisi atau kebiasaan turun-temurun masyarakat lokal dan diyakini mempunyai fungsi. Ungkapan-ungkapan tersebut disarikan dari pengalaman panjang masyarakat yang dimunculkan dari kecerdasan lokal menjadi kebijaksanaan bersama masyarakat. Sebagai sebuah tradisi dan folklor lisan, maka ungkapan tradisional mempunyai nilai-nilai yang dijabarkan dari pandangan hidup masyarakat pembuatnya. Dengan mengambil nilainilai ungkapan tradisional, maka masyarakat bisa memahami bagaimana nenek moyang atau masyarakat yang menghasilkan ungkapan tersebut memandang dan menyikapi hidup. Agar tercipta keselarasan dan keharmonisan, oleh karena itu secara umum masyarakat Jawa dipandang sebagai masyarakat yang selalu berpijak pada terciptanya harmoni manusia dengan Tuhan, sesamanya,

masyarakat,

dan

lingkungan. ${ }^{5}$

Terkait dengan persoalan interaksi antarmanusia, terutama kerukunan hidup dalam masyarakat, menurut John Haba6, setidaknya ada enam signifikansi serta fungsi sebuah kearifan lokal jika hendak dimanfaatkan sebagai salah satu bentuk pendekatan dalam menyelesaikan sebuah konflik. Pertama, sebagai penanda identitas sebuah komunitas. Kedua, elemen perekat (aspek kohesif) lintas warga, lintas agama dan kepercayaan. Ketiga, kearifan lokal tidak bersifat memaksa atau dari atas (top down), tetapi sebuah unsur kultural yang ada dan hidup dalam masyarakat. Karena itu, daya ikatnya lebih mengena dan bertahan. Keempat, kearifan lokal memberikan warna kebersamaan bagi sebuah komunitas. Kelima, local wisdom akan merubah pola pikir dan hubungan timbal balik individu dan kelompok, dengan meletakkannya di atas common ground/kebudayaan yang dimiliki. Keenam, kearifan lokal dapat

\footnotetext{
5 Sri Harti Widyastuti, "Reaktualisasi Ungkapan Tradisional Jawa sebagai Sumber Kearifan Lokal dalam Masyarakat untuk Penguat Kepribadian Bangsa", makalah, Konggres Bahasa Jawa ke-5 dikutip dalam http://ki-demang.com/kbj5 , diunduh 14 Oktober 2017.

6 Dalam Alpha Amirrachman, Revitalisasi Kearifan Lokal: Studi Resolusi Konflik di Kalimantan Barat, Maluku dan Poso, (Jakarta: ICIP dan European Commission (EC), 2007), h. 334-335. Dapat diakses pada www.lsaf.org/content/view/176/150/ , diunduh 17 Oktober 2017.
} 
berfungsi mendorong terbangunnya kebersamaan, apresiasi sekaligus sebagai sebuah mekanisme bersama untuk menepis berbagai kemungkinan yang meredusir, bahkan merusak, solidaritas komunal, yang dipercayai berasal dan bertumbuh di atas kesadaran bersama, dari sebuah komunitas terintegrasi.

\section{Ungkapan Tradisional Masyarakat Jawa}

Budaya Jawa yang menekankan hidup rukun menjadikan masyarakat berupaya menjaga kerukunan tersebut. Nilai-nilai budaya Jawa, seperti sikap penghormatan, sikap rukun, toleransi, dan sebagainya menjadi acuan moral dan tingkah laku dalam berhubungan antarumat beragama. Pengalaman panjang orang Jawa dalam menjalani kehidupan bersama, berinteraksi dengan sesama manusia, pencapaian tujuan pribadinya maupun tujuan bersama menjadikan orang Jawa arif dalam menjalaninya. Nilai budaya ini diungkapkan dalam berbagai tradisi yang didalamnya mengandung kearifan lokal dalam menjalani hidup bersama. Tradisitradisi tersebut menjadi kristalisasi kecerdasan masyarakat Jawa menghadapi persoalan hidup yang muncul dalam hubungannya dengan sesama manusia.
Di antara tradisi masyarakat yang menyimpan kearifan lokal tersebut adalah tradisi lesan yang berupa ungkapan-ungkapan tradisional. Menurut Dananjaya ${ }^{7}$, ungkapan tradisional ini awalnya dinyatakan secara spontan, kemudian menjadi kebiasaan dan dapat dikatakan klise. Makna dalam ungkapan ini dapat bersifat instruktif, inperatif, ataupun preventif. Biasanya ungkapanungkapan tradisional bersifat anonim atau tidak diketahui siapa penciptanya. Ciri-ciri lainnya dari ungkapan tradisional ini adalah:

1. Merupakan alat pencerminan suatu angan-angan yang bersifat kolektif;

2. Sebagai alat pengesahan pranata;

3. Sebagai media pendidikan nonformal;

4. Sebagai alat pemaksa dan pengawas, agar norma-norma masyarakat dapat dipenuhi.

$$
\text { Ungkapan tradisional adalah }
$$
kata atau kelompok kata yang memiliki makna kiasan, konotatif, simbolis yang berasal dari tradisi atau kebiasaan turun-temurun masyarakat lokal dan diyakini mempunyai fungsi. Ungkapanungkapan tersebut disarikan dari

\footnotetext{
7 Samidi Khalim, Tradisi Lisan Masyarakat Jawa, (Semarang: Prima Media Press, 2009), h. 33.
} 
pengalaman panjang masyarakat yang dimunculkan dari kecerdasan lokal menjadi kebijaksanaan bersama masyarakat. Sebagai sebuah tradisi dan folklor lisan, maka ungkapan tradisional mempunyai nilai-nilai yang dijabarkan dari pandangan hidup masyarakat pembuatnya. Dengan mengambil nilainilai ungkapan tradisional, maka masyarakat bisa memahami bagaimana nenek moyang atau masyarakat yang menghasilkan ungkapan tersebut memandang dan menyikapi hidup. Agar tercipta keselarasan dan keharmonisan, oleh karena itu secara umum masyarakat Jawa dipandang sebagai masyarakat yang selalu berpijak pada terciptanya harmoni manusia dengan Tuhan, sesamanya, masyarakat, dan lingkungan. ${ }^{8}$

Dengan demikian, ungkapanungkapan tradisional dalam masyarakat memiliki peran sebagai acuan moral dalam menjalani kehidupan bersama secara rukun dan damai, sekaligus menjadi media transformasi nilai-nilai kerukunan tersebut pada masyarakat dan generasi selanjutnya. Masyarakat menjalani interaksi sosialnya dengan

8 Sri Harti Widyastuti, "Reaktualisasi Ungkapan Tradisional Jawa Sebagai Sumber Kearifan Lokal dalam Masyarakat untuk Penguat Kepribadian Bangsa", makalah, Konggres Bahasa Jawa ke-5 dikutip dalam http://ki-demang.com/kbj5 , diunduh 14 September 2017. orang lain akan dinilai dari kesesuaiannya dengan nilai-nilai moralitas tersebut. Oleh karena itu, ungkapanungkapan tradisional dalam masyarakat Jawa tidak hanya berupa ungkapan yang bernada positif, tetapi juga menggunakan istilah negatif sebagai bentuk kritik terhadap perilaku yang negatif tersebut. Ungkapan-ungkapan tersebut, baik yang positif maupun negatif sama-sama memiliki fungsi sebagai acuan moral, tentang apa yang baik dan buruk dalam perilaku manusia dalam kehidupannya.

Ungkapan Jawa terinci dalam banyak jenis, diantaranya berupa: wangsalan, parikan, sanepa, tembung entar, paribasan, bebasan, dan saloka. Wangsalan itu adalah ungkapan yang ungkapan sejenis tebakan atau tekateki yang jawaban atau tebakannya berupa suku kata tersamar di dalam tubuh ungkapan itu sendiri. Parikan adalah ungkapan yang memiliki aturan persajakan, sampiran, isi, dan jumlah baris yang dibutuhkan. Sanepa adalah ungkapan yang berfungsi untuk menggambarkan situasi atau keadaan secara berlebih atau menyangatkan dengan cara pengandaian. Tembung entar adalah ungkapan yang maknanya kiasan, berbentuk perumpamaan, dan 
berfungsi untuk menyindir tingkah laku atau sifat seseorang.

Paribasan adalah ungkapan yang digunakan secara ajeg/tidak boleh diganti, serta tidak berupa perumpamaan, fungsinya untuk menggambarkan keadaan, tingkah laku atau kehendak seseorang. Bebasan merupakan ungkapan yang berisi perumpamaan, diungkapkan secara ajeg, dan berfungsi untuk mengungkapkan keadan dan tingkah laku orang yang digambarkan.

Fokus perumpamaan terletak pada tingkah laku dan keadaannya. Saloka adalah ungkapan yang menggambarkan perilaku dan keadaan seseorang dengan perumpamaan. Adapun yang dianalogikan/ diperumpamakan adalah orangnya. ${ }^{9}$

Selain jenis pengungkapan tersebut, masih terdapat jenis lainnya seperti pepali ora ilok dan kereta basa atau jarwa dhosok. Pepali ora ilok merupakan bentuk larangan melakukan sesuatu yang dipandang tidak baik atau berakibat tidak baik bagi pelakunya. Sedangkan kereta basa atau jarwa dhosok adalah mengandaikan makna

9 Endang Nurhayati, "Nilai-Nilai Luhur dalam Ungkapan Jawa sebagai Fondamen Kehidupan Masyarakat Berbudaya", makalah, Konggres Bahasa Jawa ke-5 dikutip dalam http://kidemang.com/kbj5 , diunduh 14 September 2017. dari nama sesuatu atau kata tertentu dengan menganggapnya sebagai akronim dengan kepanjangannya sebagai makna yang dimaksud.

\section{Refleksi Akhir}

Masyarakat Indonesia memiliki budaya-budaya dan tradisi-tradisi lokal yang secara fungsional mampu menjaga situasi lingkungannya agar tetap harmonis, baik dengan sesama manusia maupun lingkungan. Tradisi-tradisi lokal tersebut memiliki makna dan nilai penting diantaranya sebagai acuan tingkah laku bagi masyarakatnya dalam menjalani kehidupan, termasuk menghadapi perbedaan-perbedaan dalam berinteraksi dengan orang lain yang berbeda budaya. Tradisi-tradisi lokal tersebut sesungguhnya merupakan pengungkapan pengetahuan lokal (local knowledge) atau kearifan lokal (local wisdom) dari suatu masyarakat dalam menanggapi situasi lingkungannya.

$$
\text { Masyarakat Balun Desa Balun }
$$
Kecamatan Turi Kabupaten Lamongan mampu memelihara kerukunan umat beragama, meskipun berbeda agama. Hal ini disebabkan adanya elemen-elemen yang menjadi perekat sosial berupa kearifan-kearifan lokal yang hidup dalam masyarakat Balun. 
Secara substansial, kearifan lokal adalah nilai-nilai yang berlaku dalam suatu masyarakat. Nilai-nilai tersebut diyakini kebenarannya dan menjadi acuan dalam bertingkah laku sehari-hari masyarakat setempat. Nilai-nilai kearifan lokal ini dipandang sebagai entitas yang sangat menentukan harkat dan martabat manusia dalam komunitasnya karena di dalamnya berisi unsur kecerdasan kreativitas dan pengetahuan lokal dari para elit dan masyarakatnya.

\section{Daftar Pustaka}

Amirrachman, Alpha. 2017. Revitalisasi Kearifan Lokal: Studi Resolusi Konflik di Kalimantan Barat, Maluku dan Poso, Jakarta: ICIP dan European

Commission (EC), 2007, www.lsaf.org/content/view/176/ 150/ diunduh 17 Juni 2017.

Geertz, Hildred. 1985. Keluarga Jawa. Jakarta: Grafiti Press.

Haba, John. 2007. Revitalisasi Kearifan Lokal: Studi Resolusi Konflik di Kalimantan Barat, Maluku, dan Poso. Jakarta: ICIP dan Eropean Commision.
Khalim, Samidi. 2009. Tradisi Lisan Masyarakat Jawa. Semarang: Prima Media Press,.

Marsh, David dan Gerry Stoker. 2002. Theory and Methods in Politial Science. Hampshire: Palgrave Macmilla.

Nurhayati, Endang. 2012. "Nilai-Nilai Luhur dalam Ungkapan Jawa sebagai Fondamen Kehidupan Masyarakat Berbudaya", makalah, Konggres Bahasa Jawa ke-5 dikutip dalam http://kidemang.com/kbj5 ， diunduh 14 September 2017.

Rohimin, et.al,. 2009. Harmonisasi Agama dan Budaya di Indonesia. Jakarta: Balai Litbang Agama Jakarta.

Suseno, Franz Magnis, Etika Jawa, Sebuah Analisa Falsafi tentang Kebijaksanaan Hidup Jawa, (Jakarta: PT. Gramedia Pustaka Utama, 2003), h. 38.

Widyastuti, Sri Harti. 2012. "Reaktualisasi Ungkapan Tradisional Jawa Sebagai Sumber Kearifan Lokal dalam Masyarakat untuk Penguat Kepribadian Bangsa", makalah, Konggres Bahasa Jawa ke-5 dikutip dalam 
Jurnal Politik dan Sosial Kemasyarakatan

Vol 12 No 1 (2020) : Februari 2020

http://ki-demang.com/kbj5

diunduh 14 September 2017 